\title{
TEORIA E PRÁXIS E O ANTAGONISMO ENTRE A FORMAÇÃO POLITÉCNICA E AS RELAÇÕES SOCIAIS CAPITALISTAS
}

\author{
THEORY AND PRACTICE AND ANTAGONISM BETWEEN POLYTECNIC TRAINING AND \\ CAPITALIST SOCIAL RELATIONS
}

Gaudêncio Frigotto ${ }^{1}$

Resumo O presente texto busca explicitar a concepção de educação e de projeto de sociedade que está na origem e desenvolvimento da Escola Politécnica de Saúde Joaquim Venâncio, tarefa teórica e ético-política que se impõe com o início do Programa de Pós-graduação strictu sensu de Educação Profissional em Saúde. Enfatiza-se, nesta análise, que o tempo histórico que vivemos é de regressão no campo social, político e educacional e que, portanto, os desafios do curso de mestrado que se inicia são mais complexos. Trata-se de produzir, mediados pela teoria, a compreensão da urgência de se construir, desde agora, na disputa contra-hegemônica, processos educativos que conduzam as novas gerações a entender o caráter cada vez mais inviável da sociedade capitalista centrada na competição, desperdício, consumo e violência. Com base nesta compreensão, produzir a subjetividade coletiva da necessidade política da práxis revolucionária para a superação da sociedade capitalista.

Palavras-chave educação politécnica; regressão social; antagonismo; práxis; contra-hegemonia.
Abstract This text seeks to explain the conception of education and of society's project which is in the origin and development of the Polytechnic School of Health Joaquim Venancio, a theoretical task and a ethically based policy that imposes itself with the beginning of the Post-graduate program strictu sensu in Professional Education in Health. It is emphasized in this analysis that the historical time we live in is of regression in the social, political and educational fields and, therefore, the challenges of the master's program that is starting are more complex. It is intended to develop, based on theory, the understanding of the urgency to build educational processes that bring the new generations to understand capitalist's society's character which becomes more and more not viable and focused on competition, waste, consumption and violence, and, based on this understanding, to produce a collective understanding of the political imperative of a revolutionary approach to overcome the capitalist society.

Keywords polytechnic education; social regression; antagonism; praxis; counter-hegemony. 


\author{
Os socialistas estão aqui para lembrar ao \\ mundo que em primeiro lugar devem vir as \\ pessoas e não a produção. As pessoas não podem \\ ser sacrificadas. (...) Especialmente aquelas \\ que são apenas pessoas comuns. (...) É delas que \\ trata o socialismo; são elas que o socialismo \\ defende (Hobsbawm, 1992, p. 268).
}

O título deste texto pode parecer pretensioso ou até mesmo arrogante. Confesso que demorei muito para defini-lo. Muitas alternativas me vieram à cabeça. Mas foi este o tema que me pareceu mais adequado para estabelecer, ao mesmo tempo, um inventário que nos permita perceber, ao comemorar o aniversário da Escola Politécnica de Saúde Joaquim Venâncio (EPSJV), da Fundação Oswaldo Cruz (Fiocruz), de que conformismo somos conformistas e demarcar o horizonte teórico e ético-político do início do curso de mestrado de Formação Profissional em Saúde.

Na verdade, o título resulta, de um lado, de minha ligação intelectual, política e afetiva ao projeto da escola, à minha origem de classe e à minha formação intelectual. Um título, por outro lado, que me parece adequado na busca de interrogar o pensamento quando se inicia um passo importante e arrojado com a implantação do Programa de Pós-graduação strictu sensu de Educação Profissional em Saúde.

Um passo que se dá como resultado de um processo, mas cujo desafio é hoje bem mais complexo. Não por uma razão de hierarquia de níveis de escolaridade, mas pela materialidade regressiva das relações sociais capitalistas nos âmbitos mundial e brasileiro. Por outro lado, quando a teoria e a práxis revolucionárias tornam-se humanamente mais urgentes também se encontram, nos planos mundial e nacional, regressivas.

A questão que se coloca é de minimamente trazer para esta análise: o sentido teórico, político e educacional, particular e universal, desta experiência da EPSJV, dentro da qual nasce a proposta da pós-graduação strictu sensu; caracterizar o terreno regressivo no plano das relações sociais, no plano teórico social e educacional e no plano político; e assinalar, a título de síntese, alguns desafios teóricos e ético-políticos que esse tempo de desmedida do capital (Linhart, 2007) nos impõe como tarefa para aqueles que mantêm a utopia de construir relações sociais, não classistas. Vale dizer, construir no âmbito das contradições e dos limites desse sistema capitalista as possibilidades de processos educativos vinculados à luta de construção do socialismo.

Ao contrário do pensamento único que postula, após a derrota do socialismo real, a afirmação eterna do capitalismo, o historiador Eric Hobsbawm 
nos alerta que, mais que nunca, o socialismo deve estar em pauta. Isso pelo fato de que o capitalismo não tem condições de resolver a magnitude e abrangência dos problemas que ele mesmo produz.

Mais cedo ou mais tarde exigirão a ação sistemática e planejada nacional e internacionalmente e uma investida contra as fortalezas centrais da economia de mercado e consumo. Exigirão não apenas uma sociedade melhor que a do passado, mas como sempre sustentaram os socialistas, um tipo diferente de sociedade. Uma sociedade que não apenas é capaz de salvar a humanidade de um sistema produtivo que escapou ao controle, mas uma sociedade em que as pessoas possam viver vidas dignas de seres humanos: não apenas no conforto, mas juntos e com dignidade. É por isso que o socialismo ainda tem um programa 150 anos após o manifesto de Marx e Engels (Hobsbawm, 1992, p. 269-270).

A EPSJV tem, na sua origem, dominantemente a compreensão de tempo histórico assinalado por Hobsbawm e a convicção da urgência de se construir, desde agora, na disputa contra-hegemônica, processos educativos que conduzam as novas gerações a entender o caráter cada vez mais inviável da sociedade capitalista centrada na competição e consumo, a necessidade de sua superação.

\section{Revistando a trajetória: o que nos trouxe até aqui e qual seu sentido}

"Choque teórico", não por acaso, foi o título do seminário no qual se buscava o eixo teórico e ético-político estruturante da proposta pedagógica da Escola Politécnica de Saúde Joaquim Venâncio.

Com efeito, tratava-se de extrair dos embates teóricos construídos em alguns poucos programas de pós-graduação nas ciências humanas e sociais que revistavam autores malditos, Marx, Engels, Gramsci, Lênin, entre outros, o horizonte da educação integral, politécnica e omnilateral, num confronto antagônico com a herança histórica dominante do pragmatismo, tecnicismo e do economicismo, cujo escopo é de uma educação unilateral - educar para o mercado e formar o cidadão produtivo. ${ }^{2}$

No campo da saúde tratava-se de superar, do mesmo modo, a visão de que as políticas públicas nesta área eram para garantir a reprodução saudável da força de trabalho para o mercado. A noção de capital humano constitui-se, na década de 1950, a partir da ideia de um trabalhador treinado, adestrado e educado, com saúde para se adaptar às exigências da produção mercantil e atingir a produtividade máxima.

A perspectiva do 'choque teórico' carregava consigo um sentido e uma direção ético-política, teórica e epistemológica dentro da tradição do materialismo 
histórico. Saviani (2003), em texto que sintetiza sua exposição no seminário de origem da escola, explicita o núcleo fundamental nesse sentido e direção. O lema era de inverter o sinal ou a direção de duas décadas de ditadura civilmilitar, na sociedade e na educação. As conferências brasileiras de educação, a Associação Nacional de Pesquisa e Pós-graduação (Andep) e, mais tarde, o Fórum Nacional em Defesa da Escola Pública, em suas especificidades e particularidades, orientavam a luta concreta na disputa das concepções e da política educacional na Constituinte e, em seguida, na nova Lei de Diretrizes e Bases.

A EPSJV, sem dúvida e de forma consciente, expressava esse contexto e buscava, resgatando uma memória histórica que vai além desta conjuntura, pautar-se na tese dois de Marx sobre Feuerbach.

A questão de saber se cabe ao pensamento humano uma verdade objetiva não é uma questão de teoria, mas de prática. É na práxis que o homem deve demonstrar a verdade, isto é, a realidade e o poder, o caráter terreno do seu pensamento. A disputa sobre a realidade ou não realidade de um pensamento que se isola da práxis, mas questão puramente escolástica (Marx, 1986, p. 126).

Tratava-se, pois, de organizar uma escola com bases materiais e com uma concepção formativa capaz de cumprir o ideário gramsciano da escola unitária e da elevação moral e intelectual dos jovens para atuarem como sujeitos na sociedade em que vivem.

O campo da práxis é, por excelência, o campo da ação política. Como nos lembra Leandro Konder (1992), coube a Marx efetivar uma modificação decisiva da tríade aristotélica, 'a práxis, a poiésis e a theoria'. Tríade que marcou o pensamento ocidental numa perspectiva idealista, racionalista e do materialismo vulgar.

É partindo do legado de Hegel, mas invertendo seu idealismo, que Marx supera a herança que entende a teoria como criação pura do pensamento, e não o movimento do pensamento no seu terreno próprio de mediação na construção do conhecimento histórico. Trata-se de um esforço do pensamento para apreender o movimento, as determinações e mediações que constituem a realidade humana, a qual se coloca como desafio ou como problemática a ser compreendida.

A produção das ideias, de representações da consciência, está de início diretamente entrelaçada à atividade material e com o intercâmbio material (...) os homens são produtores de suas representações, de suas ideias etc., mas os homens reais e ativos (...). A consciência jamais pode ser outra do que o ser consciente e o ser dos homens é seu processo de vida real (Marx e Engels, 1986, p. 36).

É, também, no movimento de construção do materialismo histórico, na compreensão das relações sociais capitalistas ou do modo de produção social capitalista, que Marx, como indica uma vez mais Konder, efetiva uma modificação 
decisiva na relação entre teoria e práxis e de práxis e 'poiésis'. E essa modificação torna-se possível para Marx quando encontra na classe trabalhadora, no proletariado, o sujeito histórico ou "o portador material da revolução capaz de superar a sociedade capitalista" (Konder, 1992, p. 1003).

A tese dois de Feuerbach, acima transcrita, ganha densidade histórica. Teoria e práxis e práxis e poiésis não são realidades dicotômicas. Teoria deixa de ser uma pura abstração que idealiza o real. Práxis não se reduz à atividade prática ou ativismo e poiésis mera produção material, produção de objetos. Teoria histórica, práxis revolucionária e poiésis, expressões da atividade vital dos seres humanos, vinculam-se a um projeto de superação do modo de produção capitalista para a sociedade sem classes, o socialismo. Uma superação cujo teor está sintetizado nas teses dez e 11 sobre Feuerbach.

O ponto de vista do antigo materialismo é a sociedade 'civil'; do ponto de vista do novo (materialismo) é a sociedade humana ou a humanidade socializada (Marx, 1986 p. 14).

Os filósofos têm apenas interpretado o mundo de maneira diferente; a questão, porém, é transformá-lo (Marx, 1986, p. 14).

A educação politécnica ou tecnológica e o trabalho como princípio educativo, nas poucas passagens da obra de Marx e Engels, não estão vinculados a dimensões especificamente dos projetos e métodos pedagógicos, e sim à concepção dos processos sociais e educativos, que de dentro do terreno contraditório e numa perspectiva antagônica às relações sociais capitalistas pudessem desenvolver as bases sociais, culturais e científicas das múltiplas dimensões do ser humano no horizonte da práxis revolucionária, para a transição a um novo modo de produção e organização da vida social.

Esse entendimento já está enunciado na tese três de Feuerbach.

A doutrina materialista de que os seres humanos são produtos das circunstâncias e da educação, [de que] seres humanos transformados são, portanto, produto de outras circunstâncias e de uma educação mudada, esquece que as circunstâncias são transformadas precisamente pelos seres humanos e que o educador ele próprio precisa ser educado. Ela acaba, por isso, necessariamente, por separar a sociedade em duas partes, uma das quais fica elevada acima da sociedade (por exemplo, em Roberto Owen).

A consciência de mudar as circunstâncias e da atividade humana só pode ser tomada e racionalmente entendida como práxis revolucionária (Marx, 1986, p.12).

Por essa compreensão podemos perceber o caráter falso do legado do economicismo, que situa a educação como um capital (humano) motor do 
desenvolvimento e da superação da desigualdade entre nações e entre classes ou grupos sociais, sem alterar as relações de poder e de classe (as circunstâncias) que produzem a desigualdade. Do mesmo modo, o pensamento iluminista e voluntarista de que se pode, pela educação, separada das circunstâncias e da práxis revolucionária, adquirir uma consciência crítico-prática. E, por fim, das visões que por não entenderem que as relações sociais não classistas implicam um processo de superação, dentro das contradições da sociedade de classe, conduzem ao imobilismo ou ao teorismo.

E o trabalho é princípio educativo porque é através dele que o ser humano produz a si mesmo, produz a resposta às necessidades básicas, imperativas, como ser da natureza (mundo da necessidade), mas também e não separadamente às necessidades sociais, intelectuais, culturais, lúdicas, estéticas, artísticas e afetivas (mundo da liberdade). ${ }^{3}$

As circunstâncias históricas permanecem sob o jugo da cisão do gênero humano em classes sociais. As relações sociais dominantes buscam reduzir o trabalho humano de atividade vital a mercadoria força de trabalho. Uma mercadoria cujo valor se define no mercado do emprego - compra e venda de força de trabalho. No interior destas relações sociais a educação, de direito social e subjetivo, tende a se reduzir a uma preparação psicofísica, intelectual, estética e afetiva subordinada às necessidades unidimensionais da produção mercantil.

Neste revistar a concepção que orientou a criação da escola politécnica da Fiocruz, percebemos, também, que a 'utopia' constituiu-se na força de superação tanto do determinismo do fim da história quanto do teorismo, voluntarismo e ativismo sem direção. Utopia, cujo sentido não é de não estar em nenhum lugar ou num terreno ilusório, mas estar num outro lugar. Não se trata de uma teleologia determinista e nem iluminista, mas de uma utopia cuja teleologia se produz mediante a compreensão histórica do caráter mutilador das relações sociais capitalistas e de suas contradições estruturais insanáveis e cada vez mais agudas. 4

A trajetória desses mais de vinte anos já foi e vem sendo matéria de análises e estudos sob diferentes pontos de partida e intencionalidades. Mesmo estando implicado de diferentes formas nessa trajetória, não como profissional vinculado ao seu cotidiano, a tomo como objeto de pesquisa para, entre outros aspectos, buscar qualificar o que é uma escola média de qualidade na ótica do capital e do mercado capitalista brasileiro, e na ótica que, mesmo estando dentro desta realidade, busca superá-la. ${ }^{5}$ 


\section{O caráter regressivo das relações sociais capitalistas, da teoria social e educacional e da luta política}

Assinalei acima que o curso de mestrado da EPSJV começa numa conjuntura regressiva no plano da base material das relações sociais capitalistas, no âmbito da política e da teoria social e educacional. Certamente tal acontece, mas essa diferença muito pouco acrescentaria em termos de aprofundamento de análise.

Vou ser aqui apenas esquemático porque há análises densas disponíveis na literatura internacional e nacional sobre a natureza regressiva das relações sociais em todos os âmbitos no contexto da mundialização do capital, da ideologia neoliberal ou do discurso único. 6

A regressão da base material das relações sociais explicita-se, no plano mais geral, por aquilo que no fato de, como nos lembra Fredric Jameson (1996), a contradição entre o avanço das forças produtivas e o caráter opaco das relações sociais, é bem mais candente hoje do que quando Marx elaborou sua análise sobre a natureza e o desenvolvimento do modo de produção capitalista.

Com efeito, a nova base tecnológica e organizacional, que Harvey (1998) denomina de capitalismo flexível, não só dispensa milhares de trabalhadores na produção direta, aumentando o desemprego estrutural e precarizando o trabalho/emprego no mundo inteiro, como exacerba a exploração combinando a mais-valia absoluta e relativa para os que estão empregados. Por outro lado, as taxas de crescimento, especialmente dos países do capitalismo central, mas não só, se dão à custa da degradação da natureza e, portanto, das bases da vida.

A outra face dessa regressividade é a hipertrofia do capital financeiro e do capital fictício, focalizando o desenvolvimento dentro de uma lógica financista e rentista. Os balanços anuais dos bancos nos fornecem dados inequívocos sobre essa hipertrofia.

Em síntese, como nos mostra Mészáros (2002), à estratégia da destruição criativa analisada por Schumpeter (1982) o sistema capitalista agrega hoje a produção destrutiva. A primeira consiste na dinâmica da competitividade intercapitalista de introduzir incessantemente os avanços científico e técnico no processo produtivo, e destruindo os velhos processos técnicos antes mesmo de esgotarem sua utilidade social. A segunda se caracteriza, sobretudo, pelo caráter destrutivo. Para manter-se e para prosseguir, o sistema capital funda-se cada vez mais num metabolismo do desperdício, da 'obsolescência planejada', na produção de armas, no desenvolvimento do complexo militar, na destruição da natureza, na produção de 'trabalho supérfluo'; vale dizer, desemprego em massa. Além disso, dentro das políticas de ajuste para recuperar as taxas de lucro, nas últimas décadas vem abolindo quase todos os direitos dos trabalhadores conquistados ao longo do século XX (Mészáros, 2002). 
Essa regressividade tem efeitos bem mais funestos sobre a vida de milhões de seres humanos em sociedades, como a brasileira, de capitalismo dependente e de desenvolvimento desigual e combinado. ${ }^{7} \mathrm{O}$ pensamento social crítico de Caio Prado Junior (1976), Florestan Fernandes (1981), Francisco de Oliveira (2003), entre outros, nos mostra o caráter falso da visão dualista ou sublinhada por Edmar Bacha (1974), com a fábula da Belíndia. O Brasil seria uma composição de uma pequena Bélgica rica, moderna, e uma Índia atrasada, semianalfabeta, com valores tradicionais e com um enorme contingente de trabalhadores na informalidade. A parte Índia seria responsável pelo atraso, subdesenvolvimento e que impediria de nos tornarmos um país de capitalismo avançado.

Ao contrário, o pensamento social crítico nos mostra que se trata de uma construção social que define a forma específica de nosso capitalismo dependente e subordinado. Uma sociedade cuja opção de desenvolvimento desigual e combinado pressupõe o analfabetismo, a escola dual com uma educação empobrecida para as massas, a informalidade e a desigualdade.

A radicalização dessa opção, palco de resistências e de lutas políticas ao longo do século XX, define-se como hegemônica a partir da década de 1990, durante os dois mandatos do governo de Fernando Henrique Cardoso, e mantém-se, no seu núcleo estrutural, inalterada no governo de Luis Inácio da Silva, não obstante sua origem operária e ter sido eleito dominantemente por forças sociais e políticas vinculadas à resistência a esse modelo. 8

Isso nos indica, por certo, a necessidade de irmos, em nossas avaliações, além das análises conjunturais e descermos ao plano do tecido estrutural de um capitalismo que potencializa a memória da colonização, do longo período escravocrata forjando uma classe burguesa predatória e violenta cuja matriz de pensamento é, como mostra Caio Prado, o mimetismo, a cópia, enriquece menos pelo trabalho e mais pelo assalto ao fundo público, endividamento externo e pela exponencial exploração do trabalho.

A regressão no plano das teorias social e educacional é de dupla natureza. Como nos mostra Leda Paulani (2006), no âmbito da teoria econômica, o percurso de Fredric Hayek, expressão mais avançada do pensamento conservador, nos dá a natureza dessa regressão. Por mais de meio século Hayek debateu-se para resolver o conflito entre a suposta liberdade de escolha do indivíduo e a natureza das relações sociais capitalistas dentro da teoria econômica clássica e neoclássica. Ao concluir que o enigma por essa via não se resolvia, formulou uma doutrina - o neoliberalismo. Doutrina que não apenas regride ao credo do liberalismo conservador, comprovadamente fracassado pelo que nos mostra Eric Hobsbawm (1995) no seu balanço do século XX, no livro Era dos extremos, mas assenta as políticas econômica e social num receituário que anula as políticas keynesianas cujo objetivo foi corrigir, na ótica capitalista, o credo liberal conservador. 
Mais amplamente e de forma concomitante, a outra regressão no campo abrangente das ciências sociais efetiva-se pelo ideário do pós-modernismo. Este, como nos mostra Fredric Jameson (1996), é expressão cultural do capitalismo tardio. Vale dizer, da fragmentação da realidade pela produção flexível e por uma radicalização do individualismo. Por apreender a face fenomênica do capitalismo flexível, o pós-modernismo corrobora a tese de Margareth Thatcher de que não via a sociedade, e sim indivíduos. Como consequência, estaríamos no fim das classes sociais, do proletariado e ingressando na sociedade pós-industrial, pós-classista, pós-política e pós-moderna - sociedade do conhecimento. 9

Essa dupla regressão se potencializa no campo educacional e se materializa na ideologia das competências e da empregabilidade. Trata-se de traduzir, no plano educacional, um ideário onde não há lugar para todos e o problema não é coletivo, mas individual. As competências a serem desenvolvidas e que garantem empregabilidade são as que o mercado reconhece como as que tornam cada trabalhador o máximo produtivo. O capital agora não só se interessa pela força física, mas também pelas qualidades intelectuais, emocionais e afetivas. De resto, o empregável tem a qualidade mercantil de ser flexível e de permanecer com garantia de emprego apenas enquanto funcional ao seu empregador. Uma pedagogia que apaga a memória de organização, de coletividade e também de direito ao trabalho.

Como consequência, encobre as relações de poder e de classe na produção da desigualdade social e instaura o senso comum da ideologia do capital humano e da pedagogia das competências, que colocam a educação e a qualificação como saída ao desemprego ou subemprego e à pobreza. Tanto a ideologia do capital humano quanto a da pedagogia das competências encobrem o fato de que os pobres, desempregados ou subempregados têm pouca e precária escolaridade por sua condição de classe explorada.

A regressão dos referenciais teóricos não afetou tão-somente o campo conservador. Como sublinha Jameson (1997), no terreno da tradição do marxismo, a crise manifesta-se pelo frequente abandono da busca da compreensão das contradições e conflitos, e migra-se para o campo das antinomias e das análises dicotômicas ou estruturalistas.

A regressão política resulta, em grande parte, da crise de horizonte teórico e se funda na produção do individualismo e perda do horizonte coletivo e na doutrinação ideológica pelos aparelhos de hegemonia, mormente a grande mídia, de que com a derrota do socialismo real (lida como fracasso eterno) não há alternativa à sociedade mercantil. Trata-se do fim de outra história possível, ou seja, de relações sociais não classistas. No plano das relações sociais cotidianas, a regressão política manifesta-se na tese da autonomia das decisões econômicas da atividade e luta política. A tese da independência dos bancos centrais não é outra senão a de que aos cidadãos comuns a atividade política se reduz ao voto, e que nem mesmo este pode ter interferência 
nas decisões econômicas. A política econômica passa a ser a única que realmente vale e esta tem de ser feita por especialistas. Esses especialistas são os que têm o mercado como regulador das relações sociais.

Esse cenário regressivo aqui assinalado quer sublinhar que os estudos de pós-graduação, como mencionamos no início deste texto, se desenvolvem hoje num terreno mais opaco do que no contexto de mais de vinte anos atrás e, portanto, com desafios mais complexos. Entretanto, o breve inventário aqui feito não visa a passar a ideia de que o sistema capitalista e seus intelectuais detêm a fórmula eterna de se redimir de suas crises cada vez mais agudas e resultantes de suas contradições. Isso não só nos conduziria ao imobilismo como à aceitação da tese do fim da história, vale dizer da utopia de uma superação das relações capitalistas. Pelo contrário, os mais de vinte anos da EPSJV são um sinal vivo de que a luta contra-hegemônica não só é necessária como possível.

Com efeito, nas conclusões da pesquisa Educação tecnológica e ensino médio: concepções, sujeitos e a relação quantidade/qualidade (Frigotto, 2008), a escola destaca-se por situar-se entre as melhores do país na qualidade do ensino pelo que denominamos bases materiais e projeto pedagógico. Todavia, é a proposta que com maior clareza destaca em seus ideários pedagógico e ético-político o compromisso de formar sujeitos emancipados, capazes de buscar a construção de novas relações sociais que transcendam a cidadania e democracia liberais, sob as relações sociais capitalistas.

\section{Uma síntese possível ou quais os desafios para renascer das cinzas}

Talvez a metáfora 'renascer das cinzas', utilizada por Eric Hobsbawm (1992) após fazer um balanço da derrocada do socialismo real, seja apropriada para uma breve síntese final. Ao contrário da agenda neoliberal e pós-moderna, que por caminhos diversos afirma o capitalismo tardio de mundialização do capital, a utopia de superação das relações capitalistas continua em pauta pelas razões que esse autor nos coloca e que destacamos na epígrafe. Por isso que, ao contrário do pensamento dominante hoje, esse historiador sustenta de forma enfática que um projeto de 'desenvolvimento sustentável' não pode operar através do mercado, mas deve operar contra ele.

Daqui decorre uma primeira síntese, a de que a educação politécnica ou tecnológica necessita desenvolver, mesmo numa realidade que lhe é adversa, uma formação científica, técnica e política cujo conteúdo, método e forma expressem uma direção antagônica à perspectiva de subordinação unidimensional às relações sociais e educativas capitalistas. Isso, contudo, não pode ser decorrente de uma doutrinação, mas por aquilo que Gramsci (1978) aponta como elevação moral e intelectual das massas. 
A segunda síntese é a de que o curso de mestrado constitui-se num espaço de elaboração onde as teorias social e educacional podem nos ajudar a perceber que as burguesias mundial e brasileira, por limites do seu modo fragmentário de conceber e de analisar a realidade social, não têm a chave mágica de barrar as contradições que elas mesmas produzem e nem de anular a luta, por mais aguda que seja hoje, da classe trabalhadora. Não cabe aqui explorar essas contradições, onde, sem dúvida, a destruição de direitos, a degradação do meio ambiente, o governo do mundo pelo medo e violência não são sinais de força deste sistema, mas de debilidade e limite.

Sinalizo, a título de exemplo, apenas as contradições que a burguesia mundial e, especificamente, a burguesia brasileira enfrentam para ajustar os trabalhadores às necessidades do sistema produtivo.

Numa síntese de estudos e de pesquisa empírica sobre a crise do trabalho/ emprego na França, Sibele Linhart (2007) mostra-nos que a adoção das novas tecnologias no processo de produção e no campo organizacional defronta-se com a contradição da necessidade de um trabalhador colaborativo, capaz de trabalhar em equipe, mas cuja formação é cada vez mais individualista, assentada na ideia de que não há lugar para todos e que o sucesso depende apenas do desenvolvimento de suas competências.

No âmbito da burguesia brasileira, por sua opção de associação subordinada às burguesias dos centros hegemônicos, esses limites apresentam-se de forma mais candente. De tempos em tempos, produz-se um vozerio reclamando do sistema educacional e de seus professores pela falta de profissionais qualificados. Os reclamos mais recentes, ao final de 2007, se dão no contexto do Plano de Aceleração do Crescimento (PAC), cuja meta é o crescimento do Produto Interno Bruto (PIB) de aproximadamente $5 \%$ ao ano. O pesquisador Celso Pastore cunhou a expressão 'apagão educacional' para referir-se ao déficit de trabalhadores qualificados demandados nessa conjuntura. O senador Cristovam Buarque, ex-ministro da Educação, sugeriu uma Comissão Parlamentar de Inquérito (CPI) do 'apagão'. A própria metáfora impactante de 'apagão educacional' dá a entender algo conjuntural e momentâneo e que pode ser corrigido rapidamente, talvez por um novo programa emergencial.

$\mathrm{O}$ fato de a burguesia brasileira não perceber que o que ela denomina de apagão educacional não é conflitante e nem paradoxal com o tipo de relações sociais que ela mesma produz, e advém, portanto, de uma contradição de suas práticas, revela a posição de uma classe atrasada, violenta e subordinada aos centros hegemônicos do sistema capital. A falta de jovens qualificados e, ao mesmo tempo, de jovens que buscam desesperadamente emprego e qualificação e o assustador número de jovens, os melhores qualificados, que saem anualmente em busca de trabalho, 10 resultam das contradições de uma sociedade que, como vimos, a miséria, o mercado informal, o analfabetismo ou a escolaridade precária são condições de sua forma de ser. 
O grito de apagão educacional reitera, e de forma cada vez mais cínica, uma cultura de violência societária que culpa a vítima por sua desgraça. $\mathrm{O}$ analfabeto, o sem-terra, o subempregado, o não qualificado, o não empreendedor ou o não 'empregável' assim o são porque não souberam ou não quiseram ou não se esforçaram em adquirir o 'capital humano' ou as 'competências' que os livrariam do infortúnio e seriam a mão-de-obra qualificada para o crescimento acelerado.

O curso de mestrado é, por excelência, um espaço que cobra a produção intelectual crítica. Florestan Fernandes, num contexto em que analisa a burguesia brasileira, fala-nos do intelectual divergente e nos mostra que o desafio é o de "repor o intelectual no circuito das relações e conflito de classe (...). Mas, de nada adiantaria uma retórica ultrarradical de condenação e de expiação: o intelectual não cria o mundo no qual vive. Ele já faz muito quando consegue ajudar a compreendê-lo e explicá-lo, como ponto de partida para sua alteração real"' (Fernandes, 1980).

Ao sublinhar a importância de revistar o legado do materialismo histórico e a necessidade de dar-lhe densidade histórica não reside no fato de que o mesmo seja o único referencial que faz a crítica ao sistema capitalista, mas porque, como enfatiza Jameson (1994), é o único que se propõe a uma crítica radical a esse sistema e coloca a necessidade da práxis revolucionária para superá-lo.

Para grande parte daqueles que viveram esta experiência da EPSJV e se concordarem com o sentido e direção da leitura aqui expostos, facilmente perceberão ainda hoje a justeza da análise de Marx para quem, como vimos, nenhuma teoria, mesmo que revolucionária, muda a realidade histórica por si. O que muda é a práxis. E no plano da práxis atuamos numa realidade histórica que não é fruto de uma escolha de acordo com nossa vontade, mas como resultado de uma realidade produzida nas relações de força. Mas, lembra-nos Marx, são os seres humanos que produzem essa realidade e que, portanto, são eles que podem mudá-la. No processo de luta contra-hegemônica, o ponto crucial que nos desafia, na teoria e na práxis, é o de distinguir as mudanças que concorrem para alterar estruturalmente as relações sociais capitalistas daquelas que as alteram para conservar.

O pequeno embrião de mais de vinte anos abarca hoje centenas de jovens que, ao sair desta escola, por certo, não estarão somente preparados científica e tecnicamente para fazer bem feito o que o mercado lhes pede. Na sua experiência pedagógica e na cultura institucional, tiveram e têm a possibilidade de entender por que é fundamental desenvolver todas as dimensões e possibilidades do ser humano, e que a ciência e a técnica devem servir ao desenvolvimento humano onde as pessoas vêm em primeiro lugar e não a produção. 


\section{Notas}

1 Professor do Programa de Pós-graduação em Políticas Públicas e Formação Humana da Universidade do Estado do Rio de Janeiro (Uerj). Doutor em Ciências Humanas (Educação) pela Pontifícia Universidade Católica de São Paulo (PUC-SP). <gfrigotto@globo.com> Correspondência: Universidade do Estado do Rio de Janeiro (Uerj), Centro de Educação e Humanidades, Faculdade de Educação, Programa de Pós-graduação em Políticas Públicas e Formação Humana (PPFH) da Uerj, Rua São Francisco Xavier, 524, bloco B, $12^{\circ}$ andar, Maracanã, Rio de Janeiro, RJ, Brasil, CEP 20550-900.

2 Para uma análise da ideologia do cidadão produtivo no pensamento educacional, ver Frigotto e Ciavatta (2006).

3 Parece-me crucial a análise de Karel Kosik para superar uma visão apenas discursiva ou antinômica entre o trabalho (mundo da necessidade) e as atividades humanas como livre criação, portanto não condicionadas pela pressão da necessidade. Kosik, após distinguir o agir humano em dois campos - num campo, ele atua sob a pressão da necessidade e se chama trabalho, enquanto no outro se realiza como livre criação e se chama arte -, mostra-nos, por um lado, sua íntima relação e, por outro, o caráter histórico desta relação onde uma mesma ação humana pode ser considerada trabalho ou não trabalho. "Uma atividade é ou não trabalho, dependendo de que seja ou não exercida como uma necessidade natural, isto é, como um pressuposto necessário à existência. Aristóteles não trabalhava. Um professor de filosofia e interpretações metafísicas de Aristóteles são um emprego ( $\mathrm{sic}$ ), isto é, uma necessidade, socialmente condicionada, de procurar os meios materiais de sustento e de existência" (Kosik, 1986 , p. 187). Por isso, conclui que "a relação entre necessidade e liberdade é uma relação historicamente condicionada e historicamente variável. É portanto perfeitamente coerente, do ponto de vista materialista, que Marx reduza o problema da liberdade à redução do tempo de trabalho, isto é, à criação de tempo livre, e neste sentido traduza a problemática de necessidade e liberdade na história em relação ao tempo de trabalho e ao tempo livre" (Kosik, 1986 , p. 187). É neste sentido que para Marx, sob o capitalismo, a luta pela redução da jornada de trabalho é central para a classe trabalhadora.

4 Como mostra István Mészáros (2007), a origem das contradições e da crise do capital hoje é de natureza mais aguda, sem precedentes na história do capitalismo, pois seus limites estão postos globalmente e não mais regional ou localmente.

5 Uma literatura crescente no campo do pensamento de esquerda tem defendido que, numa sociedade capitalista, é impossível desenvolver a educação politécnica e pensar o trabalho como princípio educativo. Vou apenas situar como a questão é apresentada, já que o leitor poderá ter uma análise mais detalhada num outro texto disponível (Frigotto, 2009).

Lessa (2007) analisa alguns aspectos de publicações de Dermeval Saviani e refere-se a um livro meu (Frigotto, 1995) para caracterizar como ilusões a compreensão de Saviani e minha sobre o caráter contraditório da ciência como força produtiva e do desenvolvimento das forças produtivas. Por essa via, afirma Lessa, "o fato de alguns dos mais significativos pedagogos de esquerda terem aderido a estas teses tornou aos educadores mais complicada e difícil a percepção da essência da transformação em curso: a passagem de um patamar mais elevado de extração de mais-valia, uma intensificação dos processos alienantes oriundos do capital" (Lessa, 2007, p. 121). Do mesmo modo, cita F. M. do Carmo para externar uma posição que ele assume: "é impossível, na lógica deste sistema, a realização de uma educação geral e politécnica, configurando desta forma como utopias educacionais as propostas que anuncia dentro do capital como capazes de formar o indivíduo omnilateral" (do Carmo, 2003, p. 121). 
Da leitura que faço das obras de Saviani e naquilo que exponho no livro citado, não encontro a possibilidade da dedução de que estejamos defendendo que dentro do sistema capitalista se apresentem as condições sociais para a educação politécnica e omnilateral e nem a posição de uma dedução linear pela qual se passaria, de forma mecânica, do desenvolvimento capitalista para, na afirmação de Lessa, "o comunismo, à sociedade regulada de Gramsci ou o reino da liberdade, famosa expressão de Marx" (do Carmo, 2003, p. 121). Não há dúvida de que estamos num contexto do sistema capital de intensificação da mais-valia relativa combinada, para os empregados, da ampliação da mais-valia absoluta, mas, como sublinhamos abaixo, também de suas contradições e limites insanáveis. Não há dúvida, do mesmo modo, que as relações sociais capitalistas são antagônicas à educação omnilateral ou politécnica. O que Lessa e do Carmo não explicam é a questão relativa ao processo de superação do modo de produção capitalista. O risco da análise de Lessa e do Carmo é de ficar no plano do que Marx critica nas teses dois e três de Feuerbach acima citadas e na tese do quanto pior, melhor. A ultrapassagem do capitalismo implica enfrentar, no plano da práxis, o pântano contraditório da dialética do velho e do novo. Como nos ensina Gramsci, velho que não quer morrer e novo que necessita nascer. Ou se começa a utopia (o outro lugar) aqui e agora no plano da contradição ou a teoria vira escolástica e no lugar da luta contrahegemônica, nos limites impostos pela realidade e pelas forças que querem mudá-la, ficaremos à espera escatológica da revolução como um juízo final. Ver, a esse respeito, a análise de Kosik (1968) sobre a dialética da moral e a moral da dialética.

Numa mesma linha de argumentação sobre o caráter cada vez mais violento do sistema capital na exploração e alienação do trabalho, Paulo Sérgio Tumolo defende a ideia de que o mesmo não pode ser considerado como princípio. Dado o conjunto de razões expostas, o trabalho não pode ser considerado como princípio educativo de uma estratégia políticoeducativa que tenha como horizonte a transformação revolucionária da ordem do capital. (...) “O trabalho só poderia ser concebido como princípio balizador de uma proposta de educação que tenha uma perspectiva de emancipação humana numa sociedade baseada na propriedade social, vale dizer, na não-propriedade dos meios de produção que, dessa forma, teria superado a divisão e a luta de classes e, por conseguinte, qualquer forma de exploração social (...)" (Tumolo, 2003). Nessa interpretação, o capital torna-se a categoria antidiluviana e não o trabalho, como o situa Marx. Por ser o trabalho a atividade mediante a qual o ser humano produz e reproduz sua existência como ser da natureza (mediação de primeira ordem), é uma categoria ontológica e histórica que não é redutível às formas históricas que assume o trabalho (trabalho escravo, trabalho abstrato). Mesmo sob essas condições, o trabalho não se reduz à pura negatividade.

${ }^{6}$ Dentre os autores que permitem aprofundar e ampliar o sentido regressivo das relações sociais dentro do metabolismo do sistema capital em sua fase mundializada e flexível, destacamos: Chesnais (1996 e 1998), Harvey (1998 e 2005), Jameson (1996 e 2001), Hobsbawm (1995 e 2000) e Arrighi (1998).

7 As categorias de capitalismo dependente e desenvolvimento desigual e combinado são centrais para entender a especificidade e particularidade de como se construiu a sociedade brasileira e a sua atual configuração nas relações sociais e sua relação com os centros hegemônicos do capitalismo. Como assinala Michel Löwy, as análises do desenvolvimento desigual e combinado introduzem uma diferença crucial com os teóricos da dependência, pois, diferente destes últimos, afirma "o caráter exclusivamente capitalista das economias latino-americanas, desde a época da colonização - na medida em que (...) trata-se mais de um amálgama entre relações de produção desiguais sob a dominação do capital" (Löwy, 1995, p. 8). Sobre capitalismo dependente e a natureza da revolução burguesa no Brasil, ver Fernandes (1975 e 1981). 
8 Para um balanço sobre as políticas de educação do governo Lula da Silva, ver Frigotto, Ciavatta e Ramos (2005).

9 Para uma análise sobre os diferentes aspectos da crise teórica na educação e, mais amplamente, nas ciências sociais e humanas, ver Frigotto e Ciavatta (2001).

10 Márcio Pochmann utiliza-se da metáfora 'o biscoito fino no olho gordo do mundo' para evidenciar que os aproximadamente 160 mil trabalhadores, a maioria jovens, que saem do Brasil anualmente em busca de emprego, são os melhores qualificados (Pochmann, apud Manir, 2007).

\section{Referências}

ARRIGHI, Giovani. O longo século XX. São Paulo: Unesp, 1998.

BACHA, Edmar. O Economista e o Rei da Belíndia: uma fábula para tecnocratas. Jornal Opinião, s/e, São Paulo, 1974.

CHESNAIS, François (Coord.). A mundialização financeira. São Paulo: Xamã, 1998.

. A mundialização do capital. São Paulo: Xamã, 1996.

DO CARMO, Francisca Maurilene. Trabalho, educação e construtivismo: considerações preliminares. In: DORTA DE MENESES, Ana Maria; FIGUEIREDO, Fábio Fonseca. Trabalho, sociedade e educação. Fortaleza: UFC, 2003.

FERNANDES, Florestan. A revolução burguesa no Brasil. Um ensaio de interpretação sociológica. 3. ed. Rio de Janeiro: Zahar, 1981. (Biblioteca de Ciências Sociais).

Vozes, 1980.

A sociologia no Brasil. Petrópolis:

Capitalismo dependente e classes sociais na América Latina. Rio de Janeiro: Zahar, 1975.

Diretrizes e bases: conciliação aberta. Revista Sociedade e Universidade. São Paulo: Andes, 1992.

FRIGOTTO, Gaudêncio. Educação e crise do capitalismo real. São Paulo: Cortez, 2005.
Educação tecnológica e o ensino médio: concepções, sujeitos e a relação quantidade/qualidade. Relatório de Pesquisa. Rio de Janeiro: Uerj/CNPq/Faperj, 2008.

. A polissemia da categoria trabalho e a batalha das ideias nas sociedades de classe. Revista Brasileira de Educação, São Paulo, Autores Associados, v. 14, n. 40, jan./abr. 2009, p. 168-194.

FRIGOTTO, Gaudêncio; CIAVATTA, Maria (Orgs.). A formação do cidadão produtivo: a cultura do mercado no ensino médio técnico. Brasilia: Inep, 2006.

(Orgs.). Teoria e educação no labirinto do capital. 2. ed. Petrópolis: Vozes, 2001.

FRIGOTTO, Gaudêncio; CIAVATTA, Maria; RAMOS, Marise. A política de educação profissional no governo Lula: um percurso histórico controvertido. Revista Educação e Sociedade. Campinas, v. 26, n. 92, out. 2005, p.1087-1113.

GRAMSCI, Antonio. Concepção dialética da história. Rio de Janeiro: Civilização Brasileira, 1978.

HARVEY, David. A condição pós-moderna. São Paulo: Loyola, 1998.

. O novo imperialismo. São Paulo: Loyola, 2005.

HOBSBAWM, Eric. O novo século. São Paulo: Companhia das Letras, 2000. 
- A era dos extremos: o breve século XX (1914-1991). São Paulo: Companhia das Letras, 1995.

Renascendo das cinzas. In: BELECKBURN, Robin (Org.). Depois da queda: o fracasso do comunismo e o futuro do socialismo. São Paulo: Paz e Terra, 1992, p. 255-271.

JAMESON, Fredric. As sementes do tempo. São Paulo: Ática, 1997.

A cultura do dinheiro. Petrópolis: Vozes, 2001.

Espaço e imagem: teorias do pósmoderno e outros ensaios. Rio de Janeiro: Editora da UFRJ, 1994.

Pós-modernismo: a lógica cultural do capitalismo tardio. São Paulo: Ática, 1996.

KONDER, Leandro. O futuro da filosofia práxis: o pensamento de Marx no século XXI. São Paulo: Paz e Terra, 1992.

KOSIK, Karel. Dialética do concreto. Rio de Janeiro: Paz e Terra, 1986.

Moral da dialética e dialética da moral. In: DELLA VOLPE, G. et al. Moral e sociedade, Paz e Terra, 1968.

LESSA, Sérgio. Trabalho e proletariado no capitalismo contemporâneo. São Paulo: Cortez, 2007.

LINHART, Sibele. A desmedida do capital. São Paulo: Boitempo, 2007.

LÖWY, Michel. A teoria do desenvolvimento desigual e combinado. Tradução de Henrique Carneiro. Actuel Marx, 18, 1995.

MARX, Karl; ENGELS, Friedrich. A ideologia alemã. São Paulo: Ciências Humanas, 1986.

MARX, Karl. Teses sobre Feuerbach. In: MARX, Karl; ENGELS, Friedrich. A ideologia alemã. São Paulo: Ciências Humanas, 1986, p. 125-128.
MÉSZÁROS, István. Para além do capital. São Paulo: Boitempo, 2002.

O desafio e o fardo do tempo histórico.

São Paulo: Boitempo, 2007.

OLIVEIRA, Francisco de. Crítica à razão dualista: o ornitorrinco. São Paulo: Boitempo, 2003.

PARIS, Carlos. O animal cultural. São Carlos: Editora da EDFSCAr, 2002.

PAULANI, Leda. O projeto neoliberal para a sociedade brasileira: sua dinâmica e seus impasses. In: LIMA, Júlio César F.; NEVES, Lucia M. Wanderley (Orgs.). Fundamentos da educação escolar no Brasil contemporâneo. Rio de Janeiro: Editora Fiocruz, 2006.

POCHMANN, Márcio. Entrevista. In: MANIR, Mônica. O biscoito fino no olho gordo do mundo. Campinas: Unicamp. Disponível em: $<$ www.unicamp.br/unicamp/unicamp $>$. Acesso em: 27 abr. 2007.

PRADO JUNIOR, Caio. Revolução brasileira. São Paulo: Brasiliense, 1987.

SAVIANI, Dermeval. O choque teórico da politecnia. Rio de Janeiro: Escola Politécnica de Saúde/Fundação Oswaldo Cruz, Revista Trabalho, Educação e Saúde, v. 1, n. 1, p. 115130, 2003.

Trabalho e educação: fundamentos ontológicos e históricos. In: Reunião Anual da Anped, 29., Caxambu, 2006. Resumos. Caxambu, Anped, 2006.

SCHUMPETER, Joseph Alois.. A teoria do desenvolvimento econômico. São Paulo: Abril Cultural, 1982.

TUMOLO, Paulo Sérgio. O significado do trabalho no capitalismo e o trabalho como princípio educativo: ensaio crítico. Revista Espaço Acadêmico, Maringá, III, ano 24, 2003. 